\title{
BMJ Open Short-term and long-term survival in critical patients treated by helicopter emergency medical services in Finland: a registry study of 36715 patients
}

$\overline{\text { Johannes Björkman, }{ }^{1,2} \text { Päivi Laukkanen-Nevala, }{ }^{1} \text { Anna Olkinuora, }{ }^{1} \text { Ilkka Pulkkinen, }{ }^{3}}$ Jouni Nurmi ${ }^{1,4}$

To cite: Björkman J, Laukkanen-Nevala $P$, Olkinuora A, et al. Short-term and long-term survival in critical patients treated by helicopter emergency medical services in Finland: a registry study of 36715 patients. BMJ Open 2021;11:e045642. doi:10.1136/ bmjopen-2020-045642

- Prepublication history for this paper is available online. To view these files, please visit the journal online (http://dx.doi. org/10.1136/bmjopen-2020045642).

Received 13 October 2020 Revised 14 January 2021 Accepted 25 January 2021

Check for updates

(c) Author(s) (or their employer(s)) 2021. Re-use permitted under CC BY-NC. No commercial re-use. See rights and permissions. Published by BMJ.

${ }^{1}$ Research and Development Unit, FinnHEMS Oy, Vantaa,

Uusimaa, Finland

${ }^{2}$ Department of Anaesthesiology and Intensive Care Medicine, University of Helsinki, Helsinki, Uusimaa, Finland

${ }^{3}$ Prehospital Emergency Care, Lapland Hospital District,

Rovaniemi, Finland

${ }^{4}$ Emergency Medicine and Services, Helsinki University Hospital and University of Helsinki, Helsinki, Finland

Correspondence to

Dr Jouni Nurmi;

jouni.nurmi@helsinki.fi

\section{ABSTRACT}

Objectives This study aimed to describe the short-term and long-term mortality of patients treated by prehospital critical care teams in Finland.

Design and setting We performed a registry-based retrospective study that included all helicopter emergency medical service (HEMS) dispatches in Finland from 1 January 2012 to 8 September 2019. Mortality data were acquired from the national Population Register Centre to calculate the standardised mortality ratio (SMR).

Participants All patients encountered by Finnish HEMS crews during the study period were included.

Main outcomes Mortalities presented at 0 to 1 day, 2 to 30 days, 31 days to 1 year and 1 to 3 years for different medical reasons following the prehospital care. Patients were divided into four groups by age and categorised by gender. The SMR at 2 to 30 days, 31 days to 1 year and 1 to 3 years was calculated for the same groups.

Results Prehospital critical care teams participated in the treatment of 36715 patients, 34370 of whom were included in the study. The cumulative all-cause mortality at 30 days was $27.5 \%$ and at 3 years was $36.5 \%$. The SMR in different medical categories and periods ranged from 23.2 to $72.2,18.1$ to $22.4,7.7$ to 9.2 and 2.1 to 2.6 in the age groups of 0 to 17 years, 18 to 64 years, 65 to 79 years and $\geq 80$ years, respectively.

Conclusions We found that the rate of mortality after a HEMS team provides critical care is high and remains significantly elevated compared with the normal population for years after the incident. The mortality is dependent on the medical reason for care and the age of the patient. The long-term overmortality should be considered when evaluating the benefit of prehospital critical care in the different patient groups.

\section{BACKGROUND}

Prehospital critical care, especially when provided as part of helicopter emergency medical services (HEMS), is a relatively expensive part of the healthcare system. Only a small proportion of patients encountered by an emergency medical service (EMS) are in need of-and may potentially benefit fromprehospital critical care. ${ }^{1-3}$ Thus, identifying

\section{Strengths and limitations of this study}

- This is, to our knowledge, the first and largest study describing the short-term and long-term mortality following helicopter emergency medical service (HEMS) care.

- In addition, our study describes the standardised mortality ratios for different medical conditions and age groups.

- We combined data from two robust databases: the national HEMS database and the Population Registry Centre.

- The participants in the study were unsystematically selected.

- Our study does not describe the short-term and long-term quality of life after prehospital critical care.

these patients and targeting the service optimally is essential for a maximised cost-benefit ratio. However, currently, the evaluation of the potential benefits of physician-provided prehospital critical care and comparisons between the different treatments available are almost solely based on short-term outcomes. Examples of reported outcomes that have been used are the rate of survival to hospital admission, survival to hospital discharge and 30-day survival. ${ }^{3-6}$

As demonstrated in hospital-based critical care, some short-term survivors may be characterised by a noticeable overmortality rate within $1-3$ years. ${ }^{7-9}$ The association between age and long-term outcome is dependent on the medical reason for the critical care. A survival rate that corresponds to that of the general population has been reported in elderly patients surviving to hospital discharge after out-of-hospital cardiac arrest (OHCA), whereas elderly patients with severe traumatic brain injury are characterised by overmortality. ${ }^{1011}$ 
Outcomes after prehospital critical care may be worse compared with those following in-hospital critical care because some patients die before hospital admission. Moreover, in the prehospital setting, the information available about the patient's condition and previous state is limited. Thus, the receiving hospital might revoke intensive care if it is considered futile. The different working environments makes prognostication tools and comparison of published literature from in-hospital critical care rather irrelevant.

In this study, we describe the short-term and long-term mortality in patients treated by HEMS critical care teams in Finland for the different medical reasons. We also identify key factors associated with mortality in different age groups and patient categories in relation to the standardised mortality ratio (SMR).

\section{METHODS}

\section{Study design}

We conducted a registry-based retrospective study including all patients treated by HEMS teams in Finland from 1 January 2012 to 8 September 2019. Patients were identified from the national HEMS quality registry and followed up to 3 years from the national Population Register Centre.

We requested and were granted study permission from all participant hospital districts (Oulu University Hospital 200/2019 (2 July 2019), Helsinki University Hospital (HUS) HUS/280/2019 (9 July 2019), Turku University Hospital J30/19 (4 August 2019), the Hospital District of Lapland 32/2019 (22 August 2019), Kuopio University Hospital RPL 102/2019 (22 August 2019) and Tampere University Hospital RTL-R19580 (2 September 2019)). Permission was requested and granted by the national Population Register Centre (VRK/5613/2019-3 (1 November 2019)) to acquire the mortality data of all patients. The Strengthening the Reporting of Observational Studies in Epidemiology statement was followed in the reporting of the study. ${ }^{12}$

\section{Setting}

EMS, including HEMS, is part of the publicly funded healthcare provided in Finland. HEMS units are primarily dispatched by the emergency response centres according to predetermined dispatch criteria (with minor regional differences). Typical dispatch criteria include OHCA, major trauma and unconsciousness of an unknown origin. The paramedic-staffed HEMS unit in Lapland is also dispatched to suspected stroke, respiratory failure and cardiovascular accidents, due to the long distances and sparse EMS grid in the area.

The HEMS units are usually dispatched by the emergency response centres simultaneously with the responding EMS units, or secondarily by the EMS units attending the call. Patients are usually transported by the attending EMS unit, with the HEMS physician escorting the patient in the ambulance.
All HEMS bases use the same database, the FinnHEMS database (FHDB), to report their dispatches. The variables logged meet—in fact, surpass-the recommended guidelines for benchmarking HEMS care. ${ }^{13-15}$ Data are logged promptly after the mission by the on-call crew; however, it is not cross-checked by a third party. The HEMS system and the FHDB have been described in more detail recently. ${ }^{16}$ Since 2012, all HEMS operations have been nationally organised by FinnHEMS.

The Population Register Centre collects data regarding citizens residing in Finland. The data registered includes age, sex, place of residence, marital status and dates of birth and death. Individual patients can be identified and followed based on a personal identification number given at birth or at gaining access to healthcare and social welfare services after immigration.

\section{Participants and outcome measures}

All patients treated by the HEMS teams from 1 January 2012 to 8 September 2019 were included in the study. Patient data were collected from the FHDB. The mortality data were acquired from the Population Register Centre on 11 November 2019.

Medical problems were identified from the FHDB and categorised as trauma, OHCA, neurological (including stroke), intoxication and other causes (dyspnoea, chest pain, obstetrical/gynaecological, infection, miscellaneous). Patients were divided into four groups by age (ie, 0-17 years, $18-64$ years, $65-79$ years and $\geq 80$ years) and also categorised by gender. The planned subgroup analyses and logistic regression confounders included the categorised medical problems, the different age categories, gender and whether airway management or vasopressors were required. The last two (ie, the need for airway management or vasopressors) were included as crude descriptors of the intensity of the prehospital critical care. Individual vital parameters and their trends were disregarded, as changes and deviations in these differ in different patient groups and are subject to interventions in their own right.

The primary outcome measures were mortality at 0 to 1 day, 2 to 30 days, 31 days to 1 year and 1 to 3 years after the prehospital event. Patients deceased at 0 to 1 days, 2 to 30 days, 1 month to 1 year, 1 to 3 years were analysed independently. This was achieved by removing the patients deceased in the chronologically earlier timespan from the consecutive groups. This allowed us to focus on one timespan individually in order to evaluate overmortality in relation to the normal population. Patients were followed until death, emigration, 3 years follow-up or 10 November 2019 (whichever came first).

\section{Statistical methods}

We calculated the mortality for each group and presented it in Kaplan-Meier charts per medical problem and age (0-9 years., $10-19$ years, $20-39$ years, $40-69$ years, $60-79$ years and $\geq 80$ years). The SMR was described using the respective reference population; for example, for the 


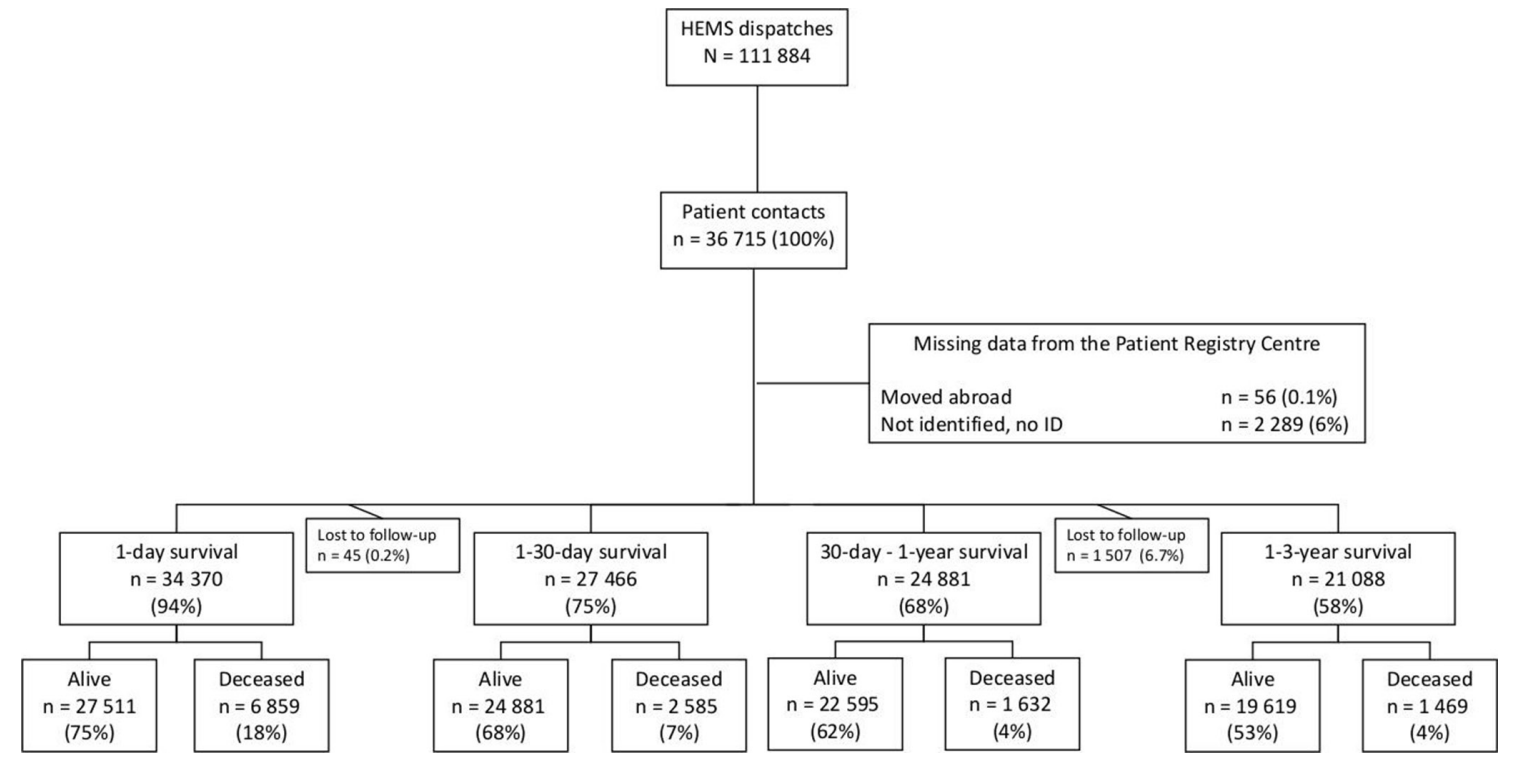

Figure 1 Flow chart of patient contact with the helicopter emergency medical services (HEMS) during the study period.

patients aged $0-17$ years at the prehospital event, the SMR at 1-3 years was compared with the general population aged (1-3) to (18-21) years. The SMR was excluded in the 1-day mortality group to exclude patients who died at the scene. This decision was made because patients who die at the scene have an intrinsically higher mortality rate than do the age-matched and gender-matched general population and do not yield any further information. Logistic regression analysis models were used to assess factors associated with mortality following the prehospital dispatch. All tests are presented as two tailed, where applicable. Data were processed using SPSS Statistics V.25 (IBM). Figures were prepared using Prism V.8 (GraphPad Prism V.8, GraphPad Software, San Diego, California, USA).

\section{Patient and public involvement}

No patient involved. Retrospective registry study, the patients or the public were not involved in the design, conduct or reporting of our findings. The study was conducted with the benefit of the patients in mind.

\section{RESULTS}

During the study period, the HEMS teams participated in the care of 36715 patients. Mortality data was acquired for 34370 (93\%) patients (figure 1). The remaining $2345(7 \%)$ either had a missing or corrupt social security number and were disregarded in the statistical analyses. Patient characteristics are presented in table 1 . Mortality rates by medical condition and by age group are presented in figure 2.

The cumulative all-cause mortality for the 3-year follow-up period was $36.5 \%$. The all-cause mortality rates for the $0-1$ days group and 2-30 days group were $20.0 \%$ and $9.4 \%$, respectively. For the 31-day to 1-year group, the all-cause mortality was $6.7 \%$, while in the $1-3$ years group, it was $7.0 \%$. For children (ie, those aged 0-17 years), the overall mortality was $6.9 \%$ (190 deaths), with a vast majority $(79.5 \%, \mathrm{n}=151)$ happening within the first day. After the first day, the mortality declined to $1.4 \%$ (39 deaths).

The associations of different medical conditions and patient characteristics with short-term and long-term mortality are presented in table 2 .

The SMRs by age groups and medical conditions are shown in figure 3. All groups had an elevated SMR throughout the follow-up period. We observed a nearly logarithmic, inversely proportional relationship when observing SMR and the different age groups. The rare

Table 1 Patientcharacteristics. data are presented as medians (IQR) and $\mathrm{N}(\%)$

\begin{tabular}{lrr}
\hline Age, years* & 57.7 & $(33.7 / 72.2)$ \\
\hline Age category, years* & & \\
$0-17$ & 3303 & $(9.0)$ \\
\hline $18-64$ & 19307 & $(52.7)$ \\
$65-79$ & 9223 & $(25.2)$ \\
$\geq 80$ & 4772 & $(13.0)$ \\
\hline Sex, male* & 23161 & $(63.9)$ \\
\hline Medical problem & & \\
\hline Trauma & 9697 & $(26.4)$ \\
OHCA & 7545 & $(20.6)$ \\
\hline Neurological & 7230 & $(19.7)$ \\
\hline Intoxication & 3638 & $(9.9)$ \\
\hline Other & 8605 & $(23.4)$ \\
\hline Prehospital procedure & & \\
\hline Rapid-sequence intubation* & 10843 & $(29.7)$ \\
\hline Vasoactive drug administration & 9023 & $(24.6)$ \\
\hline
\end{tabular}

${ }^{*}$ Data were missing for $0.3 \%-1.3 \%$ of cases.

OHCA, out-of-hospital cardiac arrest. 

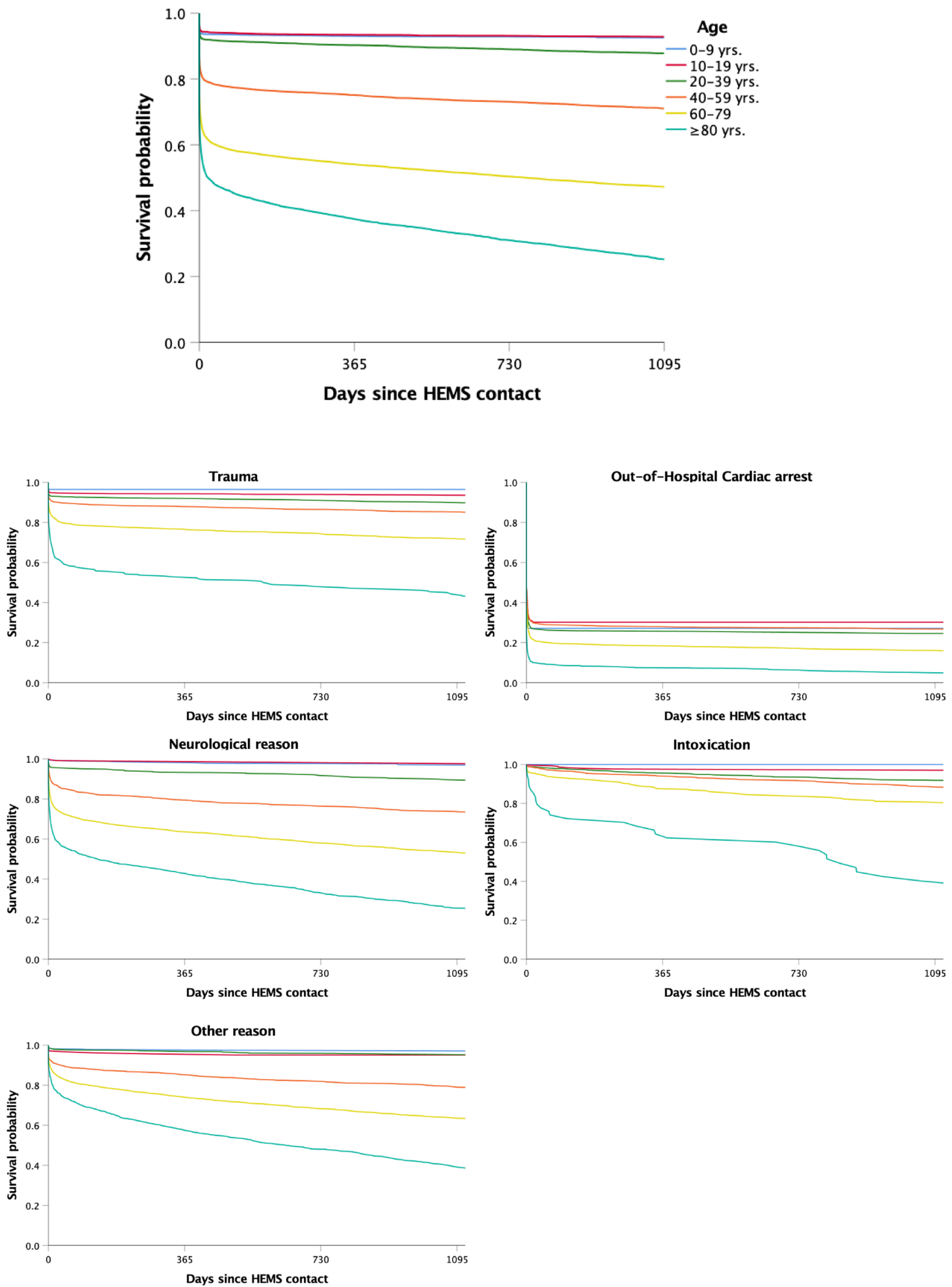

Figure 2 Kaplan-Meier survival chart per medical problem and age during the 3 years following the helicopter emergency medical services (HEMS) contact. 


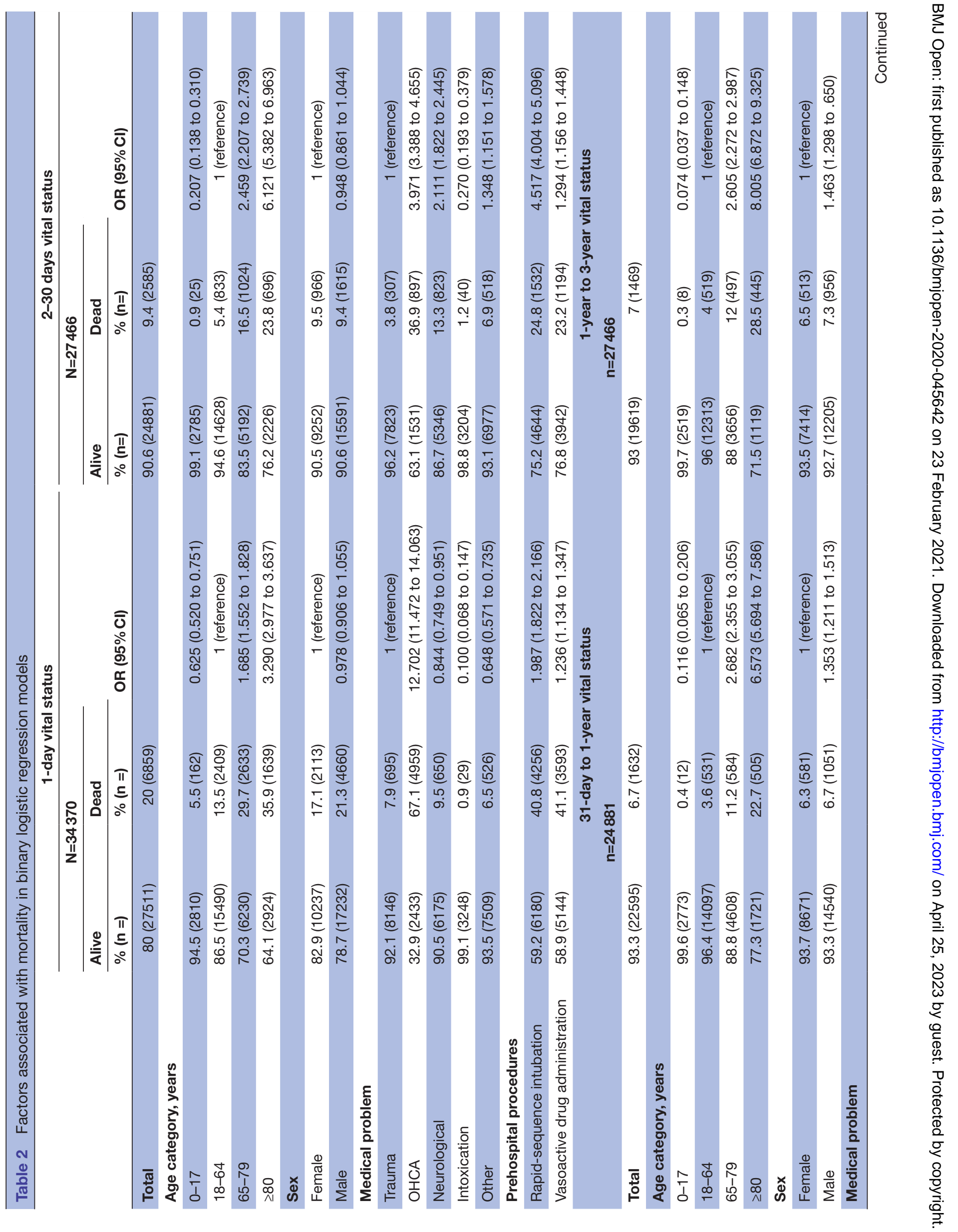



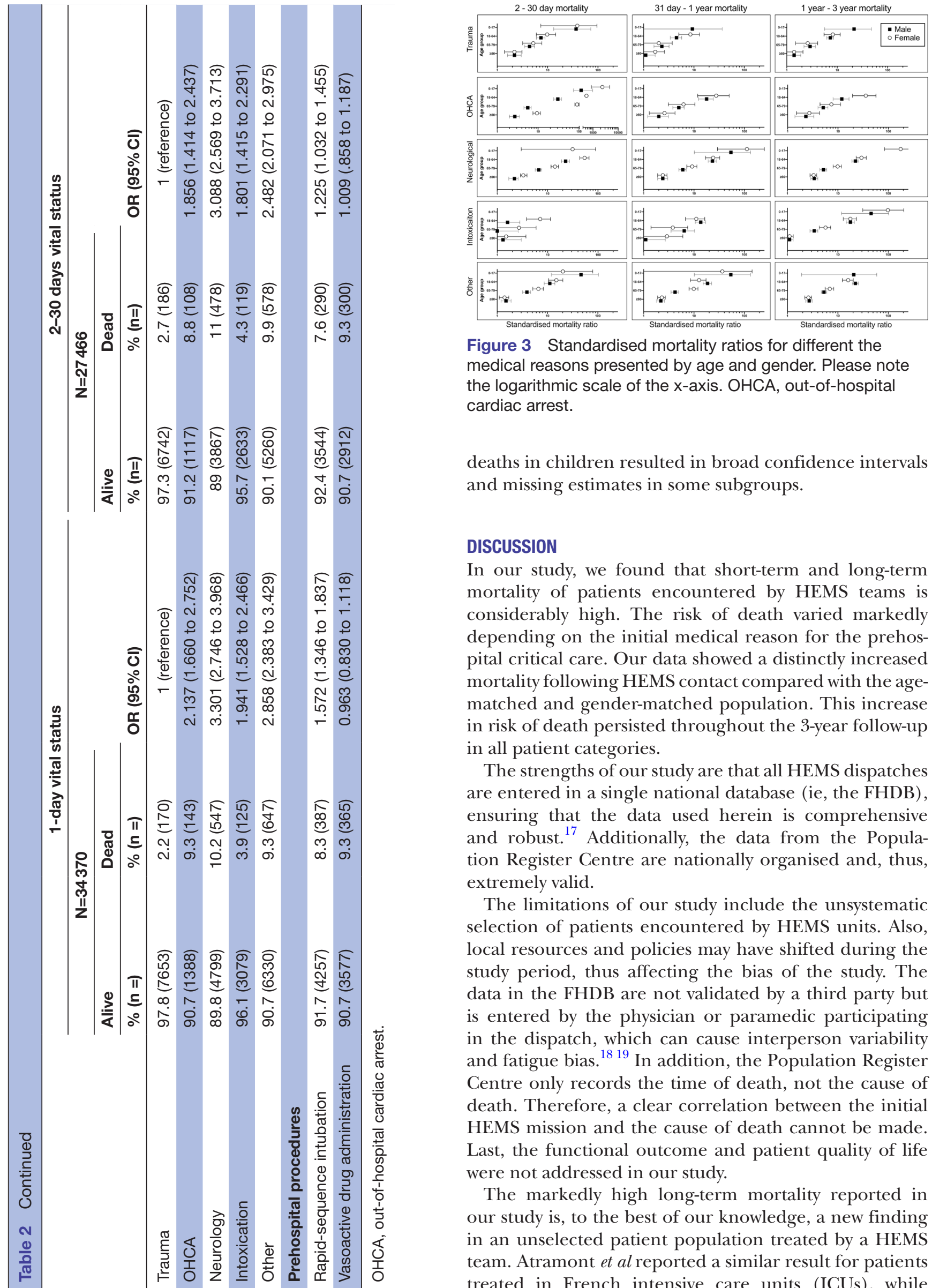

Figure 3 Standardised mortality ratios for different the medical reasons presented by age and gender. Please note the logarithmic scale of the $\mathrm{x}$-axis. OHCA, out-of-hospital cardiac arrest.

deaths in children resulted in broad confidence intervals and missing estimates in some subgroups.

\section{DISCUSSION}

In our study, we found that short-term and long-term mortality of patients encountered by HEMS teams is considerably high. The risk of death varied markedly depending on the initial medical reason for the prehospital critical care. Our data showed a distinctly increased mortality following HEMS contact compared with the agematched and gender-matched population. This increase in risk of death persisted throughout the 3-year follow-up in all patient categories.

The strengths of our study are that all HEMS dispatches are entered in a single national database (ie, the FHDB), ensuring that the data used herein is comprehensive and robust. ${ }^{17}$ Additionally, the data from the Population Register Centre are nationally organised and, thus, extremely valid.

The limitations of our study include the unsystematic selection of patients encountered by HEMS units. Also, local resources and policies may have shifted during the study period, thus affecting the bias of the study. The data in the FHDB are not validated by a third party but is entered by the physician or paramedic participating in the dispatch, which can cause interperson variability and fatigue bias. ${ }^{18}{ }^{19}$ In addition, the Population Register Centre only records the time of death, not the cause of death. Therefore, a clear correlation between the initial HEMS mission and the cause of death cannot be made. Last, the functional outcome and patient quality of life were not addressed in our study.

The markedly high long-term mortality reported in our study is, to the best of our knowledge, a new finding in an unselected patient population treated by a HEMS team. Atramont et al reported a similar result for patients treated in French intensive care units (ICUs), while 
Bøtker et al reported findings in line with the current study in an unselected Danish EMS population. ${ }^{720}$ The Danish EMS system closely resembles the Finnish system, with EMS being available to everybody. However, the results of these studies cannot be directly compared with ours. Following hospital admission, a more robust patient history, laboratory tests and medical imaging become available. Hospital resources allow for more focused patient selection, resulting in a disproportionally high prehospital mortality. Also, HEMS teams treat only the most critically ill EMS patients; thus, the results are not directly comparable.

The reasons for the high long-term mortality cannot be unrevealed based on our current study. Patients suffering from medical emergencies usually have diagnosed or undiagnosed underlying comorbidities. ${ }^{21}$ For instance, it can be argued that OHCA is usually a symptom of coronary artery disease. Coronary artery disease is, itself, a risk factor for preterm death. ${ }^{22}$ Moreover, cardiovascular risk factors, such as dyslipidaemia, smoking, genetic predisposition and obesity, are also contributing factors to neurological emergencies. Alcohol use has also been liked to increased mortality in road traffic accidents. ${ }^{23}$

The social and behavioural characteristics of the patient suffering from, for example, intoxication might put them at greater risk compared with the general population. Also, living in a lower socioeconomic area has been shown to be associated with a higher risk for trauma and subsequent EMS dispatch, especially among children..$^{24}$ Thus, the socioeconomic background of the HEMS patients could be a contributing factor for a higher risk of death when comparing them to the general population.

These factors might partially explain the increased mortality, although not entirely. Some factors, such as organisation of rehabilitation, commitment to care and sheer chance in accidents cannot be overlooked.

A majority of our patients were male, but for many groups, the SMR was equal or higher for female patients. The finding can be attributed to the longer life expectancy of women. Gender seemed not to be a risk factor for death initially, but male patients had an increased risk of death in the long term.

Paediatric patients in our study seemed to fare quite well after the initial dispatch. For example, there were no deaths of paediatric patients treated for OHCA in the long term. Of the paediatric patients, those treated for a neurological reason had the worst long-term prognosis.

Patients of working age deserve special attention. It is interesting to note that, in patients suffering from major trauma, the initial mortality was high, and subsequently, it plateaued. However, the SMR was still 10-fold even 1-3 years after the initial HEMS contact. In contrast, patients treated for intoxication had an initially low risk for death but a higher risk than those treated for trauma in the long run. This could be due to suicidal behaviour or drug addiction; however, the reason for the intoxication (eg, accidental recreational overdose or suicidal intent) is not stipulated in the FHDB.
Patients of extreme age treated by HEMS had a hopeless prognosis. However, age should not be the sole factor considered when treating critical-care patients and deciding the intensity of care to provide. The premorbid factor provides a better prognostication tool for selecting patients to admit to ICUs. ${ }^{25}$ ICUs are typically the receiving department for patients treated by HEMS. Yet, in the prehospital field, the premorbid factor can be difficult to evaluate. This, in turn, can lead to overtriage and an elevated mortality rate in the elderly. Thus, for the sake of the sustainable use of healthcare recourses, better methods to identify very old patients with a reasonable chance of survival need to be developed.

The results of our study may help clinicians in the HEMS community. The results from the logistic regression analysis might help in resource allocation in concurrent missions and in developing the dispatch criteria for HEMS teams. The short-term and long-term mortality results highlight the importance for a functioning chain of care, both in the admitting hospital and in out-patient care. Regarding the initial HEMS care, knowledge of the long-term outcome in different patient groups helps in directing care to those who benefit from it the most. Nevertheless, mortality as the only consideration may lead to suboptimal results and the marked acuity of the patients-30\% required rapid sequence intubationlimit the implementation to the whole EMS community. Thus, further studies should evaluate the functional outcomes and changes in quality of life after prehospital critical care.

\section{CONCLUSION}

Mortality after HEMS care is high and remains significantly elevated compared with the general population for years after the incident. Mortality depends on the medical reason for the prehospital care and the age of the patient. The associated long-term overmortality of HEMS patients should be taken into account when evaluating the benefit of providing prehospital critical care in different patient groups.

Acknowledgements The authors wish to thank Rosemarie Hartman and Tuukka Toivonen for their unyielding support.

Contributors JB, A0, PL-N, IP and JN participated in the planning and sketching of the study. JB conducted the analysis, interpretation and visualisation of the data and had primary responsibility of the final content. PL-N processed the data export and contributed to the data analysis and interpretation. All authors provided critical revisions and have read and approved the final manuscript.

Funding This study was funded by Helsinki University Hospital (state funding, VTR TYH2019243) and the research and development unit of FinnHEMS.

Competing interests None declared.

Patient and public involvement Patients and/or the public were not involved in the design, or conduct, or reporting, or dissemination plans of this research.

Patient consent for publication Not required.

Ethics approval Finnish legislation does not require ethical approval for registry studies. However, due to the large amount of data, including sensitive patient data, the protocol was reviewed and approved by the Ethical Board of Helsinki University (HUS/3115/2019 §194). 
Provenance and peer review Not commissioned; externally peer reviewed.

Data availability statement Data are available on reasonable request. All data relevant to the study are included in the article or uploaded as online supplemental information. An anonymised dataset with relevant variables supporting the findings may be requested from the corresponding author. johannes.bjorkman@helsinki.fi or johannes.bjorkman@finnhems.fi.

Open access This is an open access article distributed in accordance with the Creative Commons Attribution Non Commercial (CC BY-NC 4.0) license, which permits others to distribute, remix, adapt, build upon this work non-commercially, and license their derivative works on different terms, provided the original work is properly cited, appropriate credit is given, any changes made indicated, and the use is non-commercial. See: http://creativecommons.org/licenses/by-nc/4.0/.

\section{REFERENCES}

1 Butler DP, Anwar I, Willett K. Is it the $\mathrm{H}$ or the EMS in HemS that has an impact on trauma patient mortality? A systematic review of the evidence. Emerg Med J 2010;27:692-701.

2 Hesselfeldt R, Steinmetz J, Jans $\mathrm{H}$, et al. Impact of a physicianstaffed helicopter on a regional trauma system: a prospective, controlled, observational study. Acta Anaesthesiol Scand 2013;57:660-8.

3 Andruszkow H, Schweigkofler U, Lefering R, et al. Impact of helicopter emergency medical service in traumatized patients: which patient benefits most? PLoS One 2016;11:e0146897.

4 Haugland H, Rehn M, Klepstad P, et al. Developing quality indicators for physician-staffed emergency medical services: a consensus process. Scand J Trauma Resusc Emerg Med 2017;25:14.

5 Chen X, Gestring ML, Rosengart MR, et al. Speed is not everything. J Trauma Acute Care Surg 2018;84:549-57.

6 Mills EHA, Aasbjerg K, Hansen SM, et al. Prehospital time and mortality in patients requiring a highest priority emergency medical response: a Danish registry-based cohort study. BMJ Open 2019;9:e023049.

7 Atramont A, Lindecker-Cournil V, Rudant J, et al. Association of age with short-term and long-term mortality among patients discharged from intensive care units in France. JAMA Netw Open 2019;2:e193215.

8 Korosec Jagodic H, Jagodic K, Podbregar M. Long-term outcome and quality of life of patients treated in surgical intensive care: a comparison between sepsis and trauma. Crit Care 2006;10:R134.

9 Ekeloef S, Thygesen LC, Gögenur I. Short- and long-term mortality in major non-cardiac surgical patients admitted to the intensive care unit. Acta Anaesthesiol Scand 2019;63:639-46.

10 Hiemstra B, Bergman R, Absalom AR, et al. Long-term outcome of elderly out-of-hospital cardiac arrest survivors as compared with their younger counterparts and the general population. Ther Adv Cardiovasc Dis 2018;12:341-9.

11 Susman M, DiRusso SM, Sullivan T, et al. Traumatic brain injury in the elderly: increased mortality and worse functional outcome at discharge despite lower injury severity. J Trauma 2002;53:219-24.

12 von Elm E, Altman DG, Egger M, et al. The strengthening the reporting of observational studies in epidemiology (STROBE) statement: guidelines for reporting observational studies. Int J Surg 2014;12:1495-9.

13 Krüger AJ, Lockey D, Kurola J, et al. A consensus-based template for documenting and reporting in physician-staffed pre-hospital services. Scand J Trauma Resusc Emerg Med 2011;19:71.

14 Tønsager K, Rehn M, Ringdal KG, et al. Collecting core data in physician-staffed pre-hospital helicopter emergency medical services using a consensus-based template: international multicentre feasibility study in Finland and Norway. BMC Health Serv Res 2019;19:151.

15 Sunde GA, Kottmann A, Heltne JK, et al. Standardised data reporting from pre-hospital advanced airway management - a nominal group technique update of the Utstein-style airway template. Scand $J$ Trauma Resusc Emerg Med 2018;26:46.

16 Saviluoto A, Björkman J, Olkinuora A, et al. The first seven years of nationally organized helicopter emergency medical services in Finland - the data from quality registry. Scand J Trauma Resusc Emerg Med 2020;28:46.

17 Heino A, lirola T, Raatiniemi L, et al. The reliability and accuracy of operational system data in a nationwide helicopter emergency medical services mission database. BMC Emerg Med 2019;19:53.

18 Pignatiello GA, Martin RJ, Hickman RL. Decision fatigue: a conceptual analysis. J Health Psychol 2020;25:123-35.

19 Pignatiello GA, Hickman RL. Correlates of cognitive load in surrogate decision makers of the critically III. West J Nurs Res 2019;41:650-66.

20 Bøtker MT, Terkelsen CJ, Sørensen JN, et al. Long-term mortality of emergency medical services patients. Ann Emerg Med 2017;70:366-73.

21 Hirlekar G, Jonsson M, Karlsson T, et al. Comorbidity and survival in out-of-hospital cardiac arrest. Resuscitation 2018;133:118-23.

22 Proudfit WJ, Bruschke AV, MacMillan JP, et al. Fifteen year survival study of patients with obstructive coronary artery disease. Circulation 1983;68:986-97.

23 Taylor B, Rehm J. The relationship between alcohol consumption and fatal motor vehicle injury: high risk at low alcohol levels. Alcohol Clin Exp Res 2012;36:1827-34.

24 Listo I, Salmi H, Hästbacka M, et al. Pediatric traumas and neighborhood socioeconomic characteristics: a population based study. J Pediatr Surg 2020;10. doi:10.1016/j.jpedsurg.2020.05.040. [Epub ahead of print: 05 Jun 2020].

25 Pietiläinen L, Hästbacka J, Bäcklund M, et al. Premorbid functional status as a predictor of 1-year mortality and functional status in intensive care patients aged 80 years or older. Intensive Care Med 2018;44:1221-9. 